\title{
Brand Awareness and Retailer Perception of the Packaged Flour Brands
}

\author{
Smitha Nair \\ Food Safety Consultant, India
}

\begin{abstract}
The packaged flour market is growing at about 40\% per annum, according to the Ministry of Food Processing Industries. This paper studies the factors which lead to brand awareness, by a random sampling of 100 customers and 20 retailers. The paper analyses the brand awareness of a particular packaged atta brandElite atta, and also includes insights from the retailers. Recommendations to improve customer satisfaction are put forth.
\end{abstract}

Keywords: Branded Flour, customer satisfaction, brand awareness, attributes ranking, retailer study

\section{Introduction}

India is one of the world's largest food producers, yet branded foods account for an inconsequential proportion. Among the various food industry segments, the largest is wheat. The Ministry of Food Processing Industries' estimates of the industry's size vary, but it is generally put at around Rs. 80,000 crores. The market for branded atta is growing rapidly at 40 per cent per annum. The branded atta market is around 300,000 tonnes, valued at Rs. 250-275 crores. Compared to its potential, it is very small right now. According to a Tata Strategic Management Group (TSMG) report, flour is one of the top 5 fastest growing food categories, expected to reach Rs. 17,350 crore by 2015 . The packaged atta brands are presently competing on several planks, the chief one being the health plank, including fortifications, child growth, digestion, heart health, energy, general health and weight control. Inspite of this strategy, volume, affordability and proper distribution network still continues to be the chief sales driving factors (Kumar, 2010).

Considering the industry's size and low brand penetration, international giants have set their sights on the nascent Indian market for branded wheat products - biscuits, breads, packaged atta and innovations such as chappatis. This paper proposes to assess the brand awareness and retailer perception of the branded packaged atta produced by Elite Breads Pvt Ltd vis-à-vis other bread brands, by the customers in Cochin.

\section{Research Methodology}

For this study, use of both primary as well as secondary data is done. The primary data sources are the customers using these products categories respectively. Primary data is also collected from the retailers in order to understand buying behaviour and product demand patterns. The secondary data made use of include statistics released by the Ministry of Food Processing Industries regarding the packaged flour industry. Data collection methods include observation of buyer behaviour at retail shops and supermarkets, direct interview methods, use of a structured questionnaire and shopping mall intercept.

For the classification, analysis and interpretation of the primary data collected, several tools have been used. For summarizing the data, frequency distribution and measures of central value (mean, median and mode) were used. Measures of dispersion like Standard Deviation as well as cross tabulation is also used. To reveal the underlying or latent factors that determine the relationship between the observed data, the semantic differential scales are employed to measure attitudes of customers towards different competitor brands in the three segments of bread, cake and packaged Atta. The statistical analysis has been done with the help of the SPSS software. For sampling, the method of stratified random sampling has been employed. The final sample size of 100 was utilized for data analysis.

\subsection{Brand awareness}

The measures of brand awareness assume that customer recall of the brand automatically translates in to buying of the product. The customer is bombarded by the advertisements of hundreds of brands on a daily basis, with each brand jostling for a share of the customer's mind. Hence the marketer's job becomes all the more difficult in the sense that he has to ensure that the product enters the customer's conscious thought process first of all, then evokes a feeling of instant recognition and association such that the customer will pick up the product then next time he see it on the supermarket shelves. He also has to ensure that the customer has a positive opinion about the product after usage and will return back to it every time. A good marketing program hinges on their customers' satisfaction index. Hence this study focuses on the brand awareness of customers for the packaged atta brands and also includes retailer perception of the customer buying behaviour patterns. 


\section{Results and Discussion}

Analysis of the data collected showed that in the area of study, i.e. Ernakulam, the Rank $\mathbf{1}$ assigned to the Top of Mind Atta Brands was highest in the case of Pillsbury Chakki Fresh Atta, followed by Annapoorna, while Elite Atta bagged the $3^{\text {rd }}$ place. In the case of Housewife users, their preference pattern followed the general overall pattern in the matter of the first two spots, but in the case of Elite Atta, which occupied the third spot overall, it was found that married working women exhibited lower preference for it, while housewives followed the general pattern. It was interesting to note that of the total male respondents (bread earners of the family), an equal proportion voted for both Elite and Pillsbury as the top of mind Atta brands.

Table.1 - Top of Mind Packaged Atta brands Versus User Status

\begin{tabular}{|c|c|c|c|c|c|c|}
\hline \multirow{2}{*}{$\begin{array}{l}\text { Top of mind brands } \\
\text { Rank } 1\end{array}$} & \multicolumn{5}{|c|}{ User Status } & \multirow[t]{2}{*}{ Total } \\
\hline & Housewife & Married Working Lady & Student & Man of the house & Others & \\
\hline Annapoorna & 6 & 7 & 6 & 6 & 3 & 28 \\
\hline Chakra & 1 & - & - & - & - & 1 \\
\hline Elite & 5 & 2 & 2 & 7 & - & 16 \\
\hline Healthy & 1 & - & 2 & - & - & 3 \\
\hline Loose Atta & 2 & 1 & 1 & 4 & - & 8 \\
\hline Pillsbury & 7 & 11 & 3 & 7 & 1 & 29 \\
\hline Others & 3 & 7 & 2 & 2 & - & 10 \\
\hline Total & 25 & 28 & 16 & 27 & 4 & 100 \\
\hline
\end{tabular}

\section{BUYING PATTERNS FOR ATTA}

\section{Point of Purchase}

The survey revealed the statistics that $40 \%$ of the consumers purchased their packaged Atta from margin-Free markets, $20 \%$ from ordinary retail shops and 12\% from other supermarkets, while $4 \%$ were not particular about the point of purchase (Fig.2).

\begin{tabular}{|l|l|l|l|}
\hline Point of Purchase & Frequency & Percent & Cumulative Percent \\
\hline Margin Free Supermarket & 40 & 40.0 & 44.0 \\
\hline Margin free Supermarkets \& Other Supermarkets & 3 & 3.0 & 47.0 \\
\hline Margin Free Supermarket \& Ordinary Retail outlets & 3 & 3.0 & 50.0 \\
\hline Bakeries & 4 & 4.0 & 54.0 \\
\hline Other Supermarkets & 12 & 12.0 & 66.0 \\
\hline Other Supermarkets \& Ration Shops & 2 & 2.0 & 68.0 \\
\hline Ordinary Retail Outlets & 20 & 20.0 & 88.0 \\
\hline Ordinary Retail Outlets \& Ration Shops & 4 & 4.0 & 92.0 \\
\hline Ration Shops & 2 & 2.0 & 94.0 \\
\hline Others & 2 & 2.0 & 96.0 \\
\hline Not particular about Location & 4 & 4.0 & 100.0 \\
\hline Total & 100 & 100.0 & \\
\hline
\end{tabular}

\section{Purchase Frequency For Atta (Fig.3)}

The study shows that about $33 \%$ of the respondents purchased Atta once every week, while $28 \%$ purchased the same only once in a month. $8 \%$ of the respondents were non-consumers, while $18 \%$ were rare consumers. $13 \%$ consumed Atta once every fortnight.

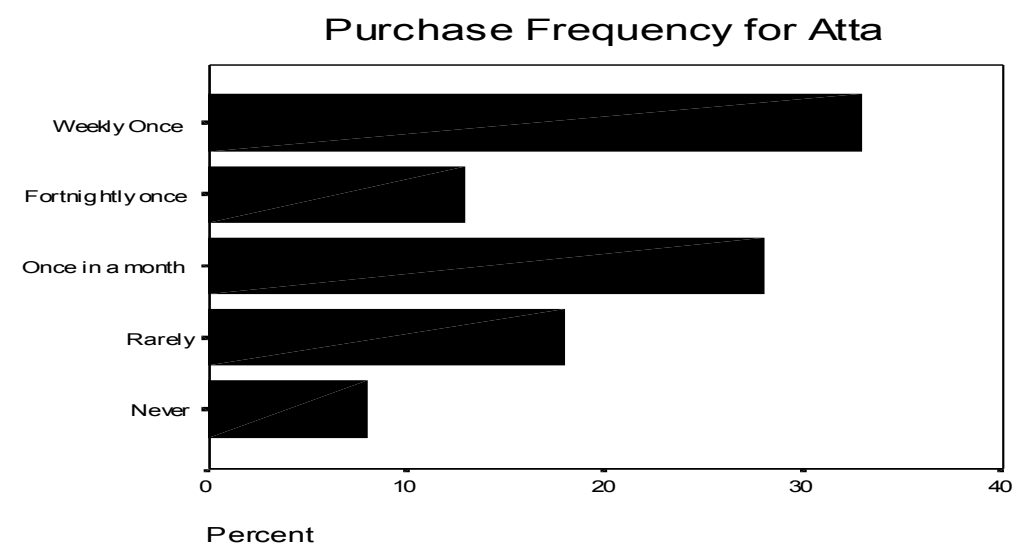


Quantity and Number of Atta Packs Used

The I Kg. Single pack was found to be the most popular pack bought by $31 \%$ of the respondents, followed by the $1 \mathrm{Kg}$. 2 packs, which had a following of $19 \%$. The $3^{\text {rd }}$ slot was taken by the 500 gms single pack having a share of $10 \%$ (Fig.4)

\begin{tabular}{|c|c|c|c|}
\hline Quantity And Number Of Atta Packs & Frequency & Percent & Cumulative Percent \\
\hline 200gms, 1 packet & 7 & 7.0 & 7.0 \\
\hline 400 gms, 1 pack & 2 & 2.0 & 9.0 \\
\hline 400 gms, 2 pack & 1 & 1.0 & 10.0 \\
\hline 500 gms, 1 pack & 10 & 10.0 & 20.0 \\
\hline 500 gms, 2 packs & 2 & 2.0 & 22.0 \\
\hline 500 gms, more than 2 packs & 2 & 2.0 & 24.0 \\
\hline 800 gms, 1 pack & 2 & 2.0 & 26.0 \\
\hline 800 gms, 2 packs & 1 & 1.0 & 27.0 \\
\hline $1 \mathrm{Kg}, 1$ pack & 31 & 31.0 & 58.0 \\
\hline $1 \mathrm{~kg}, 2$ packs & 19 & 19.0 & 77.0 \\
\hline $1 \mathrm{Kg}$, more than 2 packs & 6 & 6.0 & 83.0 \\
\hline $2 \mathrm{Kg}, 1$ pack & 1 & 1.0 & 84.0 \\
\hline $2 \mathrm{Kg}, 2$ packs & 1 & 1.0 & 85.0 \\
\hline $5 \mathrm{Kg}, 1$ pack & 8 & 8.0 & 93.0 \\
\hline $5 \mathrm{Kg}, 2$ pack & 3 & 3.0 & 96.0 \\
\hline $5 \mathrm{Kg}$, more than 2 packs & 4 & 4.0 & 100.0 \\
\hline Total & 100 & 100.0 & \\
\hline
\end{tabular}

Among the various market brands present, brand recall for Annapoorna Atta was found to be the highest at $80 \%$, followed by Elite Athulya at 73\% and Pillsbury Chakki Fresh at $72 \%$. Aashirwad registered 31\% brand recall rate, while Alpro had $22 \%$. An impressive $70 \%$ brand recall was registered by an assorted group of like Loose Atta, Ponni, Major, Chakra etc.

\section{Customer perception of Top of Mind Packaged Atta Brands}

The customers were asked to rank the top of mind Atta brands. The survey revealed that the top of mind cake brand is Pillsbury Chakki Fresh (29\%), while Annapoorna follows at a close second place with $28 \%$ while Elite Atta is at third spot with 16\%. The rest of the top of mind share is filled local brands such as Liberty, Chakra, Healthy World etc (Fig.5).

Top of mind Atta brands- Rank 1

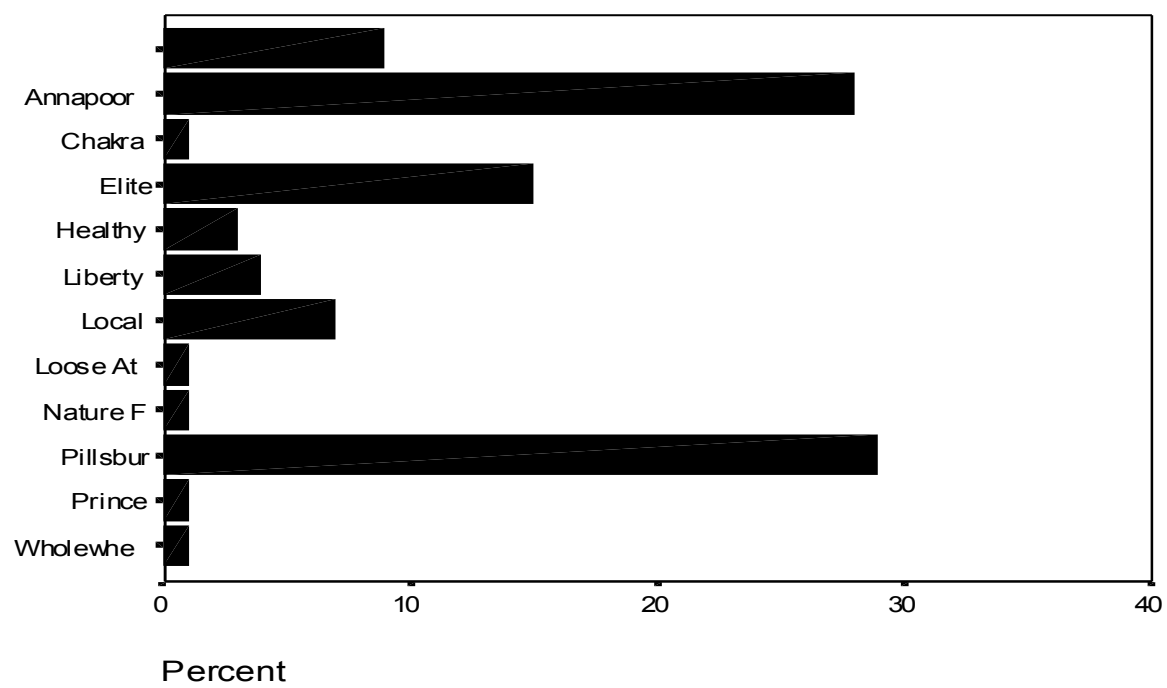

\section{Attribute Ranking for Packaged Atta by Consumers}

The customers were asked to rank the given attributes, on the basis of their importance. The attributes ranked include Low Price, Brand name, Freshness, Date of manufacture, Softness, Taste, Good Quality, Variety/Value addition, Colour, Availability, Whole wheat \% (for Atta), Packaging and Other factors (specified by the respondent). The following Fig.9 shows the ranking of the above attributes for Atta. Good quality is the most sought for attribute (13\% each), followed by freshness $(11 \%)$, date of manufacture (11\% each), brand name $(10 \%)$ etc. Low price was accorded $8 \%$, while packaging was accorded $5 \%$.

Fig.9 


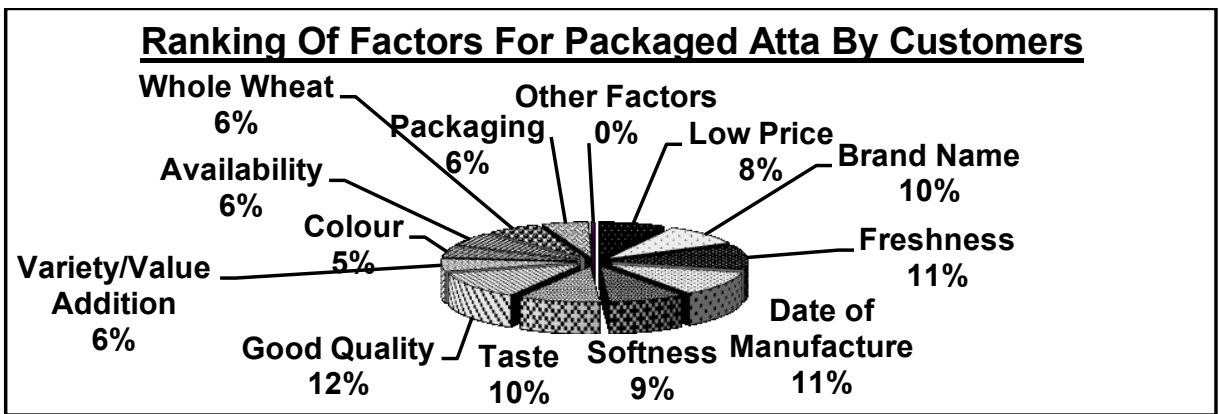

The frequency, maximum, minimum, SD and mean are given below for the attributes.

Fig.10 - Descriptive Statistics For Attributes Related To Atta

\begin{tabular}{|l|c|c|c|c|c|}
\hline & $\mathrm{N}$ & Minimum & Maximum & Mean & Std. Deviation \\
\hline Good Quality & 87 & 4.00 & 13.00 & 11.5977 & 2.0991 \\
\hline Date of manufacture & 84 & 4.00 & 13.00 & 10.8810 & 2.1699 \\
\hline Freshness & 85 & 4.00 & 13.00 & 10.6235 & 2.0701 \\
\hline Taste & 80 & 1.00 & 13.00 & 9.7875 & 2.7819 \\
\hline Softness & 76 & 4.00 & 13.00 & 9.5789 & 2.8578 \\
\hline Whole wheat \% & 55 & 2.00 & 13.00 & 9.4364 & 3.5159 \\
\hline Brand name & 83 & .00 & 13.00 & 9.3253 & 2.9055 \\
\hline Low Price & 82 & 2.00 & 13.00 & 7.9390 & 3.0403 \\
\hline Variety/Value addition & 60 & 2.00 & 13.00 & 7.5333 & 3.1594 \\
\hline Availability & 67 & 3.00 & 13.00 & 7.2985 & 3.0302 \\
\hline Colour & 63 & 3.00 & 13.00 & 6.6825 & 2.8671 \\
\hline
\end{tabular}

Preference Rating For Atta Brands

The following figure (Fig.11) shows the preference pattern governing the usage of the different Atta brands. Here, Elite Atta shows a clear lead over others with 18\% of the respondent preference share, followed by an assorted mix of other brands. Annapoorna, Ponni and Ashirvaad show a preference score of $11 \%$ each, while Pillsbury is the next most preferred Atta brand for consumption at $10 \%$.

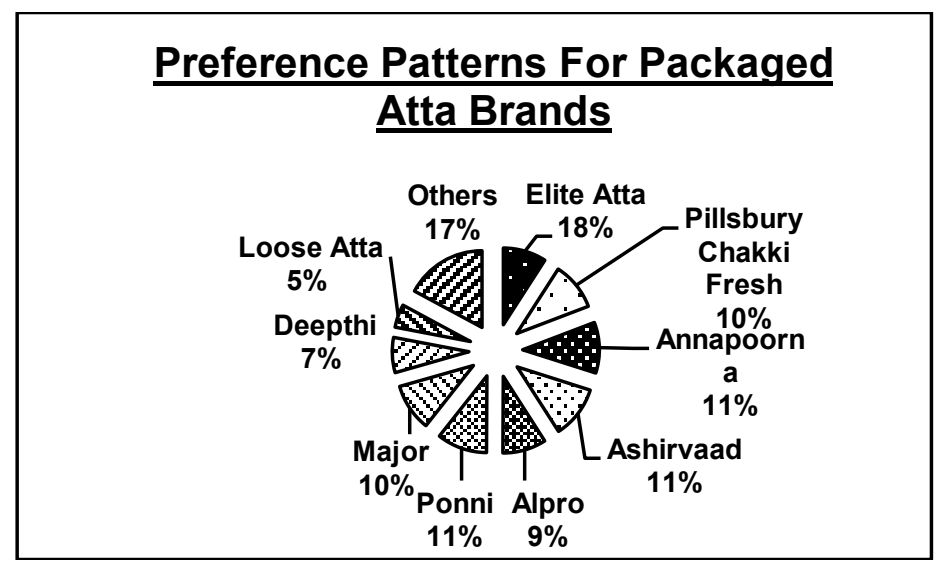

\section{Rating For Elite Atta}

In response to the query, 'How do you rate Elite Atta?'14\% of the respondents answered Very Good, $41 \%$ answered Good, 31\%found the product satisfactory, 3\% were unsatisfied with the product, while $1 \%$ had not used the product (Table.12). 


\begin{tabular}{|c|c|c|c|c|c|}
\hline \multicolumn{6}{|c|}{ Rating of Elite Atta } \\
\hline & & Frequency & Percent & Valid Percent & $\begin{array}{c}\text { Cumulative } \\
\text { Percent }\end{array}$ \\
\hline Valid & & 10 & 10.0 & 10.0 & 10.0 \\
\hline & very Good & 14 & 14.0 & 14.0 & 24.0 \\
\hline & Good & 41 & 41.0 & 41.0 & 65.0 \\
\hline & Satisf actory & 31 & 31.0 & 31.0 & 96.0 \\
\hline & Unsatisfactory & 3 & 3.0 & 3.0 & 99.0 \\
\hline & Not used & 1 & 1.0 & 1.0 & 100.0 \\
\hline & Total & 100 & 100.0 & 100.0 & \\
\hline
\end{tabular}

\section{Competitor Analysis of Major Atta Brands}

Here the competitive strengths of 4 major brands were tested, namely, Elite, Annapoorna, Pillsbury and loose Atta. The attributes tested include affordability, availability, product quality, colour and advertising. The figures represent the ratings for each of the above attributes. The ratings are on a 10-point scale, with the individual points being 2, 4, 6, 8 and 10, 10 being the highest rating and 2 the lowest.

In the case of Attribute A - Affordability, it is seen that the frequency percentage of answered queries, in the case of full points 10 is $22 \%$ for Elite and $10 \%$ for Pillsbury, 31\% for Loose Atta and 2\% for Annapoorna respectively.

In the case of Attribute B - Availability, the frequency is $28 \%$ for Elite, $13 \%$ for Pillsbury, $32 \%$ for Loose Atta and $9 \%$ for Annapoorna for the maximum 10 points.

In the case of Attribute C - Quality, 22\% scored 10 points in the case of Elite bread, while Pillsbury scored 29\%; Loose Atta secured 9\% and Annapoorna scored 11\%.

In the case of Attribute D -Colour, 16\% scored 10 points in the case of Elite, while Pillsbury got 22\%, Loose Atta $8 \%$ and Annapoorna only $5 \%$.

In the case of Attribute E - Advertising, $29 \%$ scored 10 points in the case of Elite cake, $30 \%$ in the case of Pillsbury, $1 \%$ in the case of Loose Atta and $15 \%$ in the case of Annapoorna.

The net competitive scores for the two brands are calculated to find out the product's net competitive worth. It was therefore noted that, Elite Atta leads in all the attributes except the last one - advertising, over the other three brands, namely, Pillsbury, Loose Atta and Annapoorna and therefore has a greater competitive rating than them. Pillsbury comes second in the overall rating, followed by Loose Atta and finally Annapoorna.

\section{Retailer Perception}

Twenty retailers were sampled in order to assess the buying behaviour of the consumers. All the retailers studied belonged to the supermarket category. The trend of most city dwellers to satisfy all their product requirements from under one roof - i.e. a supermarket was the underlying premise on which the sampling was based. This premise is borne out by industry studies (Anon, 2012). Therefore, twenty supermarkets in the city were included in the survey.

\section{Retailer Statistics}

Of the 20 retailers studied, 10 were between the ages of $26-40$ years, 6 between $41-60$ years and 4 belonged to the 25 years and below category. Sixteen of the retailer respondents were male and four were female. The seller status included 10 supermarkets, 4 margin free supermarkets, and 2 supplyco supermarkets and 4 small retailers.

Table 13.

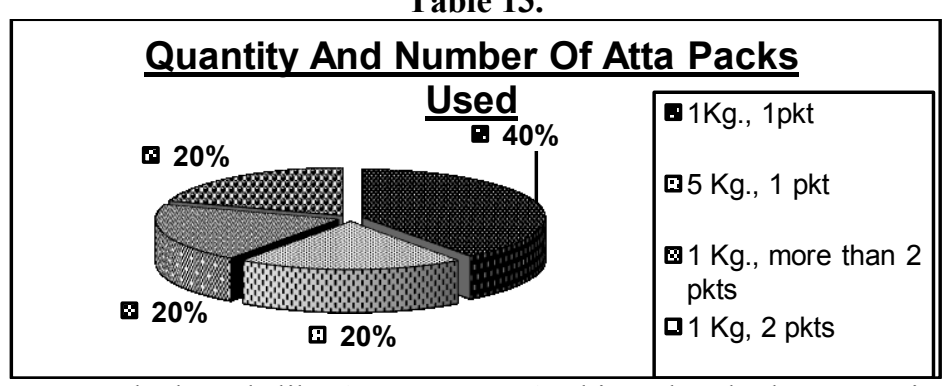

In the Packaged Atta segment, the brands like Annapoorna, Aashirwad and others constituted by Ponni, Deepthi, Major, Brahmins etc were given $100 \%$ brand recall rates. Pillsbury brand followed with $90 \%$, while Elite Athulya was given $80 \%$. 
Rating of Elite Products According to the Retailers

In the case of Elite Atta, $20 \%$ of retailers reported that it was very successful, while $40 \%$ each were of the opinion that the product is a moderate success and a success (Fig.17).

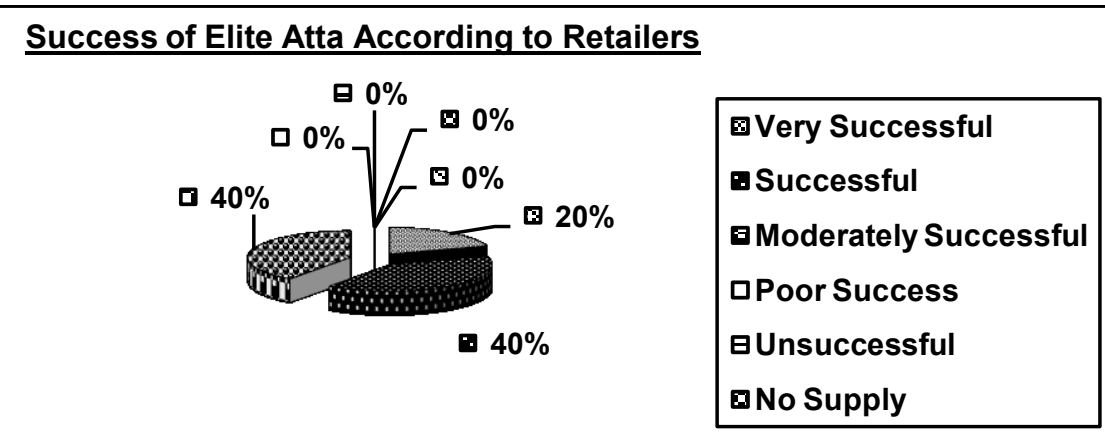

In the Packaged Atta segment, the brands like Annapoorna, Aashirwad and others constituted by Ponni, Deepthi, Major, Brahmins etc were given $100 \%$ brand recall rates. Pillsbury brand followed with $90 \%$, while Elite Athulya was given $80 \%$ (Fig.18).

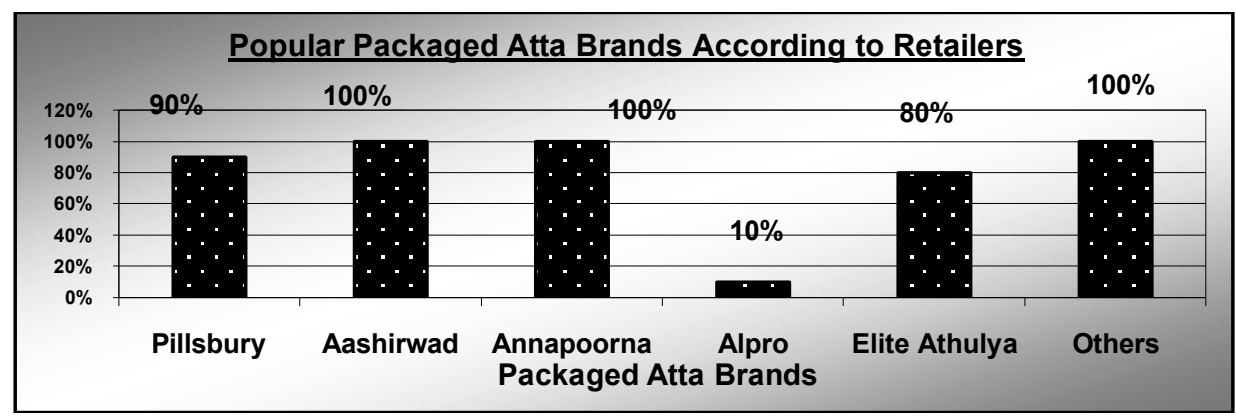

Fastest and Slowest Moving Brands of Packaged Atta

The following figures (Figs.130 -135) show the fastest and slowest moving brands for the packaged atta segment.

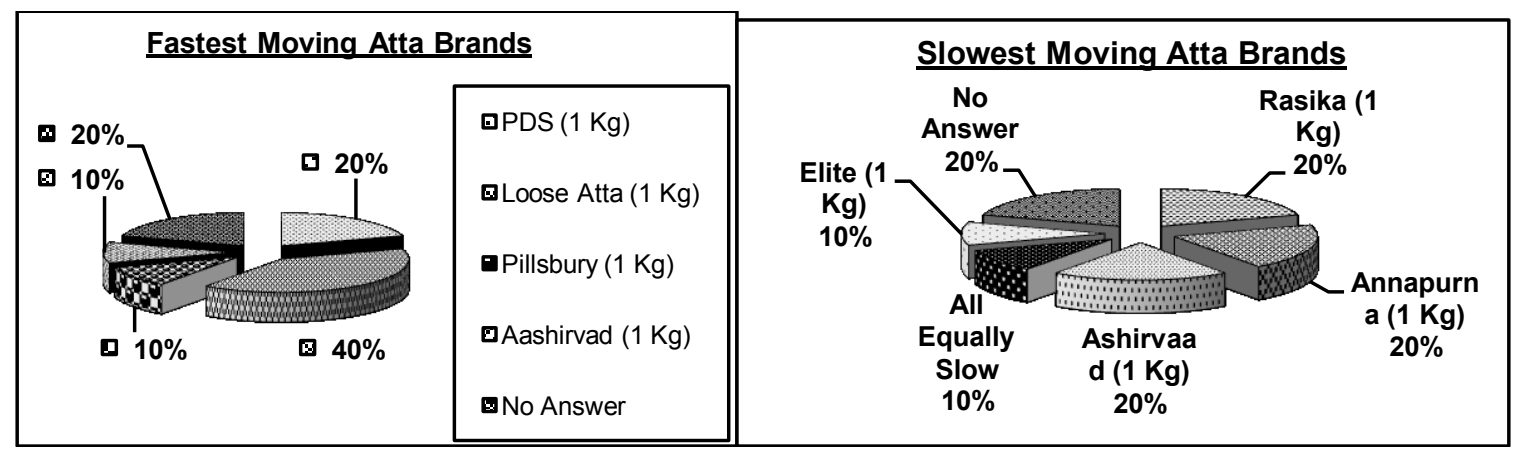

\section{Conclusions And Suggestions For Improvement}

In the case of Elite Atta, the proportion of frequent users is highest in the case of the $26-40$ year age group, as also is the proportion of regular users. Brand recall and usage rates were both 100\%. The Rank 1 assigned to the Top of Mind Atta Brands was highest in the case of Pillsbury Chakki Fresh Atta, followed by Annapoorna, while Elite Atta bagged the $3^{\text {rd }}$ place. In the case of Housewife users, their preference pattern followed the general overall pattern in the matter of the first two spots, but in the case of Elite Atta, which occupied the third spot overall, it was found that married working women exhibited lower preference for it, while housewives followed the general pattern. It was interesting to note that of the total male respondents (bread earners of the family), an equal proportion voted for both Elite and Pillsbury as the top of mind Atta brands.

The survey revealed the statistics that $40 \%$ of the consumers purchased their packaged Atta from Margin-Free markets. The study shows that about 33\% of the respondents purchased Atta once every week. The I Kg. Single pack was found to be the most popular pack bought by $31 \%$ of the respondents, followed by the $1 \mathrm{Kg}$. 2 packs, which had a following of $19 \%$. Among the various market brands present, brand recall for 
Annapoorna Atta was found to be the highest at $80 \%$, followed by Elite Athulya at $73 \%$ and Pillsbury Chakki Fresh at $72 \%$. The top of mind atta brand is Pillsbury Chakki Fresh (29\%), while Annapoorna follows at a close second place with $28 \%$ while Elite Atta is at third spot with $16 \%$. Good quality is the most sought for attribute (13\% each), followed by freshness (11\%). Elite Atta clearly leads over other brands with $18 \%$ of the respondent preference share. 14\% of the respondents rated Elite Atta Very Good, 41\% Good, 31\% found the product satisfactory, $3 \%$ were unsatisfied with the product, while $1 \%$ had not used the product. Elite Atta leads in all the attributes except the last one - advertising, over the other three brands, namely, Pillsbury, Loose Atta and Annapoorna and therefore has a greater competitive rating than them. Pillsbury comes second in the overall rating, followed by Loose Atta and finally Annapoorna.

The fastest moving Atta brand is the loose atta, available in $1 \mathrm{Kg}$ packs, followed by PDS atta, while the slowest moving atta brands, are an assorted collection, including Rasika (1 Kg), Annapoorna (1Kg) and Aashirvaad $(1 \mathrm{Kg})$, with $20 \%$ each.In the packaged Atta segment, more advertising featuring cost effectiveness and product quality, as well as the information on food safety management measures in place in the Elite factories (namely HACCP and ISO systems) will go a long way in capturing buyer attention, especially now when there is a growing awareness about food safety norms, following the implementation of the Food Safety Act by the Food Safety Standards India.

\section{References}

[1] Ministry of Food Processing Industries website http://mofpi.nic.in/ContentPage.aspx?CategoryId=184 accessed on 15.07.2013.

[2] Anon (2012), "Is Modern Trade the future growth driver for FMCG?", Equitymaster Agora Research Pvt Ltd, http://www.equitymaster.com/detail.asp?date=10/05/2012\&story=2\&title=Is-Modern-Trade-the-future-growth-driver-for-FMCG, accessed on 15.07.2013.

[3] Kumar,R. (2010), “The healthy choice”, Cover story, Consumer Trends, Pitch, April, pp. 17-24. 